\title{
Batalha química: um jogo de tabuleiro envolvendo química orgânica
}

\author{
Chemistry Battle: A Board Game Involving Organic Chemistry
}

Batalla de química: un juego de mesa que involucra química orgánica

\author{
Edemar Benedetti Filho (edemarfilho@yahoo.com.br) \\ Universidade Federal de São Carlos - Campus Sorocaba (UFSCar).
}

Alexandre Donizeti Martins Cavagis (cavagis@ufscar.br)

Universidade Federal de São Carlos - Campus Sorocaba (UFSCar).

Luzia Pires dos Santos Benedetti (luziabenedetti@yahoo.com.br)

Universidade Federal de São Carlos - Campus Sorocaba (UFSCar).

Resumo: O professor está sempre buscando novas maneiras de implementar metodologias mais efetivas ao aprendizado dos alunos, principalmente as que envolvem atividades lúdicas. Neste sentido, este trabalho teve como objetivo o desenvolvimento e aplicação de um jogo didático, envolvendo conceitos básicos de Química Orgânica relacionada à fórmula estrutural plana e nomenclaturas de alcanos. $\mathrm{O}$ jogo foi concebido para alunos do Ensino Médio, a partir de uma adaptação da tradicional "Batalha Naval", porém utilizando um tabuleiro, e incentivando a participação de todos os alunos da turma. Este relato de experiência teve uma abordagem qualitativa e quantitativa, e a coleta de dados foi realizada por meio de duas avaliações: entrevistas com os professores e anotações em diário de campo. Chamado de "Batalha Química", o jogo permitiu revisar, de forma lúdica, fórmulas estruturais planas e nomenclaturas de alcanos, propiciando um processo de ensino e aprendizagem mais prazeroso. Os alunos que participaram da atividade demonstraram grande aceitação pelo jogo, inclusive solicitando sua aplicação em outras aulas de Química, aprofundou-se a interação social e a aprendizagem da terminologia utilizada na Química de alcanos.

Palavras-chave: Jogos didáticos; Alcanos; Atividades lúdicas.

Abstract: The teacher is always looking for new ways to implement more effective methodologies for student learning, especially those involving playful activities. In this sense, this work had as objective the development and application of a didactic game, involving basic concepts of Organic Chemistry related to the flat structural formula and alkanes nomenclatures. The game was designed for high school students, from an adaptation of the traditional "Battle Naval", but using a board, and encouraging the participation of all students in the class. This experience report had a qualitative and quantitative approach, and data collection was carried out through two assessments, interviews with teachers and notes in a field diary. Called "Chemical Battle", the game allowed 143 students from two state schools to review, in a playful way, flat structural

Recebido em: 13/07/2021

Aceite em: 17/09/2021 
formulas and alkanes nomenclatures, providing a more pleasurable teaching and learning process. Students who participated in the activity showed great acceptance of the game, including requesting its application in other Chemistry classes, deepened social interaction and learning the terminology used in Alkane Chemistry.

Keywords: Didactic games; Alkanes; Playful activities.

Resumen: El docente siempre está buscando nuevas formas de implementar metodologías más efectivas para el aprendizaje de los estudiantes, especialmente aquellas que involucran actividades lúdicas. En este sentido, este trabajo tuvo como objetivo el desarrollo y aplicación de un juego didáctico, involucrando conceptos básicos de Química Orgánica relacionados con la fórmula estructural plana y nomenclaturas de alcanos. El juego fue diseñado para estudiantes de secundaria, a partir de una adaptación del tradicional "Batalla Naval", pero utilizando un tablero, y fomentando la participación de todos los estudiantes de la clase. Este relato de experiencia tuvo un enfoque cualitativo y cuantitativo, y la recolección de datos se realizó a través de dos evaluaciones, entrevistas a docentes y anotaciones en un diario de campo. Denominado "Batalha Química", el juego permitió a 143 estudiantes de dos escuelas públicas revisar, de manera lúdica, fórmulas estructurales planas y nomenclaturas de alcanos, proporcionando un proceso de enseñanza y aprendizaje más placentero. Los estudiantes que participaron en la actividad mostraron una gran aceptación del juego, incluso solicitaron su aplicación en otras clases de Química, profundizaron la interacción social y aprendieron la terminología utilizada en alcanos.

Palabras-clave: Juegos educacionales; Alcanos; Actividades lúdicas.

\section{INTRODUÇÃO}

O ensino vem constantemente passando por mudanças na busca por processos de aprendizagem que sejam mais eficientes, atrativos e participativos aos estudantes, e nessa perspectiva, a utilização de atividades lúdicas contribui para que o processo de aprendizagem atenda a estas questões, levando o aluno a "aprender brincando" (BENEDETTI et al., 2021). A inserção deste recurso didático no processo de aprendizagem dos alunos pode contribuir para, inclusive, explorar outras habilidades nas quais geralmente não são contempladas através do uso de uma metodologia menos ativa por parte do aluno, como aulas simplesmente expositivas pelo professor (COLOMBO, 2019).

As atividades lúdicas estão presentes desde o surgimento das primeiras civilizações, e geralmente se relacionam com um processo de desenvolvimento humano, como a comunicação, o registro histórico etc. Segundo Nallin (2005), desde o seu surgimento, o jogo é caracterizado por um sistema no qual os participantes presenciam conflitos 
artificiais, através de regras obrigatórias e preestabelecidas para o seu desenvolvimento, e este é o ponto importante para o processo de aprendizagem quando relacionamos os jogos e o ensino.

Estudos arqueológicos comprovam que em pinturas rupestres já haviam descrições da utilização de jogos como parte da atividade humana. Os faraós egípcios levavam para sua tumba todos os utensílios que acreditavam serem importantes para a outra vida e diversos jogos foram descobertos enterrados juntamente a eles, como o jogo de tabuleiro "Senet" (BENEDETTI FILHO; BENEDETTI, 2015). Em ruínas incas, no Peru, foram encontrados diversos brinquedos infantis dispersos pelo seu sítio arqueológico. Os jovens atenienses praticavam exercícios físicos através de atividades lúdicas, como o moderno "Cabo de guerra" ou o "Pique-pega", sendo estas mesmas brincadeiras descritas em diversas outras culturas (AMADO, 2007).

Os jogos sempre estiveram presentes no cotidiano da civilização e sua utilização como parte integrante ao ensino sempre ocorreu, principalmente para habilidades manuais e de raciocínio. Os jogos relacionados com conteúdo pedagógico, além de uma alternativa metodológica para o ensino, permitem também trabalhar diversos aspectos para melhorar as relações interpessoais na sala de aula, por meio das interações inerentes ao trabalho em equipe que tais atividades propiciam. Também podem contribuir no sentido de fortalecer a relação aluno-professor, auxiliar no desenvolvimento do raciocínio e, dessa forma, facilitar o aprendizado de conceitos nas disciplinas escolares.

Em um cenário em que o professor visa à transmissão de conteúdos e o aluno tem o papel passivo no processo de ensino e aprendizagem, as interações docente/aprendiz não estimulam o maior engajamento do estudante no que concerne à aprendizagem. Nessa perspectiva, é necessário que o professor busque meios que possibilitem aos alunos um papel ativo nesse processo. Por isso, as atividades lúdicas podem ser usadas para apresentar obstáculos e desafios a serem vencidos em grupo, o que promove o interesse e o despertar dos alunos, servindo como grande incentivo à aprendizagem. O uso de jogos pode ser um diferencial na tentativa de despertar a atenção dos estudantes para as atividades acadêmicas (MACHADO; BUZANELLO; HAMMERL, 2020).

Segundo Kishimoto (1995), as atividades lúdicas relacionadas aos jogos, especificamente, podem ser utilizadas no sistema educacional, e recebem a classificação de educativos ou didáticos. Neste contexto, os jogos educativos compõem as atividades 
desenvolvidas para ensinar um determinado conteúdo específico para a aprendizagem. Assim, o professor pode utilizar este recurso ao processo de ensino, discutindo um determinado conteúdo, sem antes ele ter sido discutido em sala de aula. Já os jogos didáticos são empregados com o objetivo de revisar os conceitos previamente discutidos em sala de aula, e sua aplicação ocorre após a aprendizagem, sendo também classificados como jogos pós-conteudistas. Geralmente os docentes os utilizam para verificar se os estudantes compreenderam os assuntos discutidos anteriormente em sala de aula e assim realizar uma avaliação para observar as possíveis falhas na aprendizagem de conteúdos teóricos.

Existem diversos estudos ressaltando a importância de atividades lúdicas, como os jogos, aplicados ao Ensino de Ciências, com as mais variadas dinâmicas (AMARAL; MENDES; PORTO, 2018; ANTUNES; PACHECO; GIOVANELA, 2012; BENEDETTI FILHO et al., 2017; BÜDY, 2012; FELÍCIO; SOARES, 2018; FRANCO, 2012; JONES; GRAHAM; SCHALLER, 2012; KAVAK, 2012Aa; KAVAK, 2012Bb; LARSON; LONG; BRIGGS, 2012; MARISCAL; MARTÍNEZ; MÁRQUES, 2012; OLIVEIRA; SOARES, 2015; OLIVEIRA; CALEJON, 2016).

Diversos conteúdos de Química exigem a memorização e o domínio de muitas regras e simbologias próprias, o que pode acarretar desinteresse ou mesmo rejeição por parte dos alunos. Por essa razão a proposta desenvolvida tem a função de diminuir o desinteresse dos estudantes para os conteúdos de alcanos e alguns problemas relatados na aprendizagem de Química (BENEDETTI FILHO et al., 2017; EASTWOOD, 2013; MOREIRA, 2013). Diversos destes jogos propostos são adaptações de jogos já tradicionais, antigos ou modernos, mas com variantes para aplicação ao ensino, e assim a proposta se adapta ao jogo de tabuleiro conhecido como "batalha naval".

O jogo "Batalha Naval" teve seu lançamento comercial publicado pela "Starex Novelty Co.", em Nova Iorque, na década de 1931, com o título de "Salvo" (Figura 1). Segundo Parllet (2018), foi um jogo idealizado por soldados russos durante a $1^{\text {a }}$ Guerra Mundial. Contudo, sabe-se que, na mesma época, soldados franceses também jogavam um jogo denominado de "L'Attaque", parecido com a batalha naval dos russos (PARLLET, 2018).

Figura 1 - Ilustração do primeiro jogo de "Batalha Naval" publicado no mercado americano. 


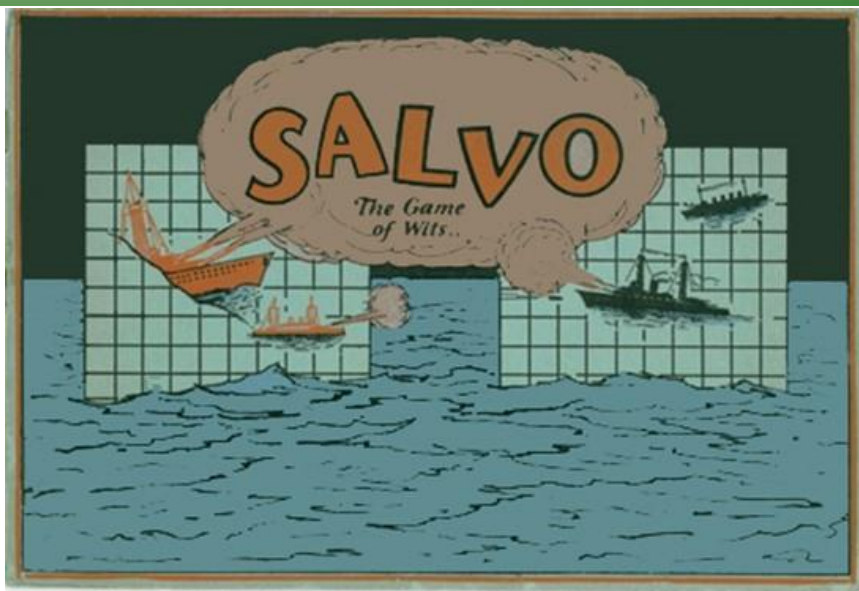

Fonte: Autoria própria.

Este texto tem como objetivo a elaboração e aplicação de uma proposta pedagógica adaptada do jogo de tabuleiro da "Batalha Naval", que denominamos "Batalha Química", visando auxiliar os alunos do Ensino Médio a rever fórmulas estruturais planas e a nomenclatura de alcanos, sendo este um dos assuntos iniciais de Química Orgânica. O intuito dessa atividade lúdica é rever e assimilar os prefixos básicos na nomenclatura desses compostos, permitindo exercitar a sua representação por meio de um processo de aprendizagem mais prazeroso e dinâmico. A atividade proposta permite montar moléculas de cadeia normal ou ramificada de diversos tamanhos, e objetiva envolver todos os alunos da sala de aula, permitindo que ocorra a interação e o aprimoramento das habilidades de convívio social.

\section{METODOLOGIA}

\section{CONSTRUÇÃO DO JOGO DE TABULEIRO}

Foi empregado o software Publisher da Microsoft Office ${ }^{\mathrm{TM}}$ (https://www.microsoft.com/pt-br/microsoft-365/publisher) para a confecção das peças, das cartas e do tabuleiro. O jogo é composto por dois tabuleiros, 50 cartas de perguntas e 400 peças, nas quais 150 são de hidrogênio, 100 de carbono e 150 de "água", uma folha de respostas para as questões. O tabuleiro é formado por uma tabela, numerada de 1 a 28 no eixo X (horizontal); e de A a S no eixo Y (vertical), no qual as estruturas orgânicas serão dispostas nos quadrados referentes às coordenadas XY, conforme 
ilustrado pela Figura 2. O tabuleiro foi impresso em impressora jato de tinta em folha sulfite A3 de gramatura $200 \mathrm{~g} / \mathrm{m}^{2}$.

Figura 2 - Tabuleiro do jogo "Batalha Química".

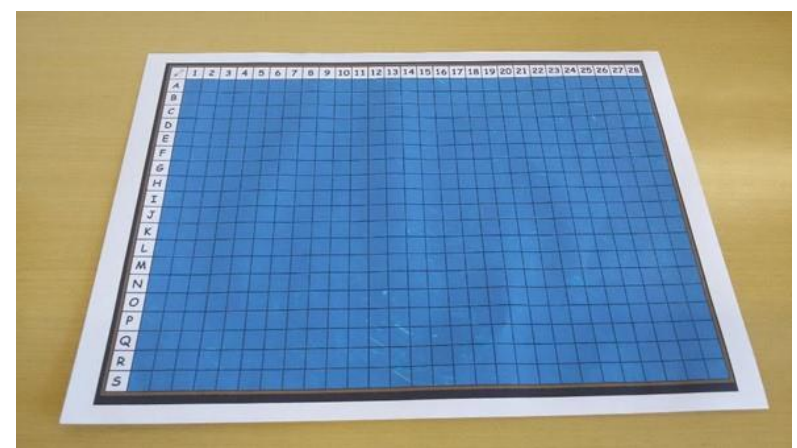

Fonte: Autoria própria.

As fórmulas estruturais planas foram impressas em sulfite A4 utilizando uma impressora jato de tinta, cortadas (representando o elemento químico carbono ou hidrogênio e suas respectivas valências) e coladas em papel cartão de gramatura $450 \mathrm{~g} / \mathrm{m}^{2}$. A Figura 3 ilustra a montagem de estruturas orgânicas dispostas no tabuleiro.

Figura 3 - Ilustração da distribuição das peças do jogo no tabuleiro e a montagem das estruturas orgânicas.

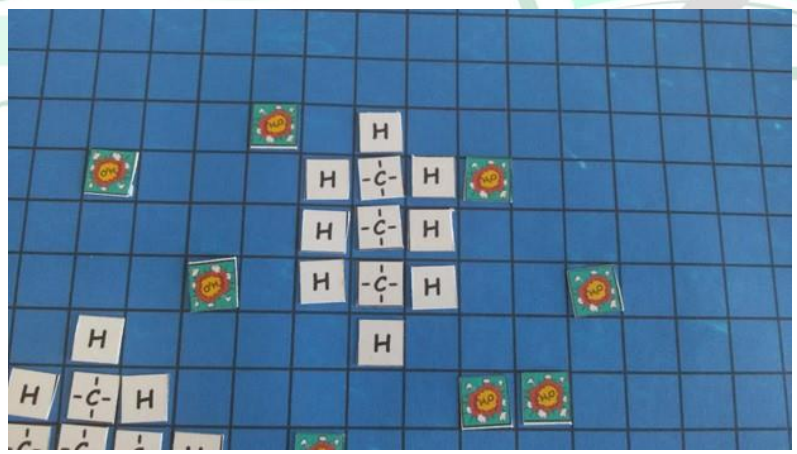

Fonte: Autoria própria.

Para o andamento do jogo, foi confeccionado um conjunto de 50 questões, envolvendo o conteúdo de Química Orgânica, sendo três alternativas de resposta para cada pergunta, tendo apenas uma correta. Cada carta apresenta uma numeração para verificar qual a resposta correta no gabarito. A figura 4 ilustra um exemplo das cartas que foram impressas em impressora jato de tinta, em sulfite A4, com o conteúdo 
envolvendo os alcanos, a arte gráfica para o verso da carta e posteriormente o envelopamento por plástico ao calor.

Figura 4 - Ilustração de algumas cartas envolvidas no jogo; pergunta na frente com as 3 alternativas por carta e uma com o verso aparente.

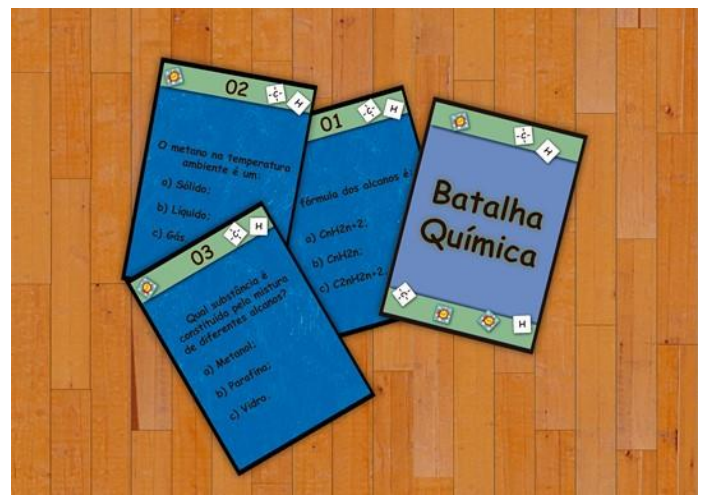

Fonte: Autoria própria.

\section{REGRAS DO JOGO "BATALHA QUÍMICA"}

Cada jogador recebe um tabuleiro e 15 peças representando os carbonos para a montagem das moléculas. Os tabuleiros devem ser separados por alguma proteção para que os jogadores não visualizem o tabuleiro do adversário. Deve ser montados no mínimo três fórmulas estruturais planas de alcanos em cada tabuleiro (como no exemplo da Figura 3) e ao menos uma deve ser ramificada. A quantidade de peças de hidrogênio deve ser a necessária para completar o número de carbono para as moléculas dispostas no tabuleiro. Após a montagem das estruturas na partida, as peças de carbono e hidrogênio deve ser guardadas e as peças de "água" colocadas ao lado dos tabuleiros. As cartas perguntas devem ser embaralhadas e colocadas com a face de fundo para cima criando um monte ao lado dos tabuleiros.

Após os jogadores decidirem quem inicia a partida, o primeiro deve retirar uma carta pergunta do monte e ler em voz alta para todos os jogadores e o adversário respondê-la. Se errar a resposta da carta passa a vez e se acertar, o jogador, realizará um lance para uma coordenada XY no tabuleiro do adversário e verificar se houve o acerto de algum átomo de carbono ou de hidrogênio. Se houver acerto de algum átomo o adversário deve dizer qual foi o átomo atingido e o nome da estrutura em que ele se encontra segundo as regras da IUPAC. Este jogador, que acertou um átomo, deve novamente responder uma nova pergunta de uma outra carta retirada do monte pelo Recebido em: 13/07/2021

Aceite em: 17/09/2021 
adversário, e proceder nesta sequência até que erre a pergunta ou não atinja nenhum átomo na escolha da coordenada XY.

O jogo mantém-se desta maneira até que todas as moléculas orgânicas do adversário sejam descobertas por um dos jogadores, assim este será considerado vencedor. Na hipótese das cartas acabarem, o jogador vencedor é aquele que descobriu o maior número de átomos do adversário. As partidas podem ser disputadas por equipes ao invés de somente 1 jogador por tabuleiro.

\section{APLICAÇÃO DO JOGO NO AMBIENTE ESCOLAR}

O jogo didático foi aplicado a 143 alunos de duas escolas públicas de Ensino Médio de uma cidade do interior do Estado de São Paulo. Previamente à aplicação do material, os pesquisadores foram às escolas realizar uma explicação do material aos professores da disciplina de Química, sugerindo sua utilização como atividade de fixação do conhecimento.

Os professores apresentaram-se receptivos a essa proposta, nos disponibilizando oito turmas para a aplicação. Três turmas na escola 1 (duas noturnas e uma diurna) e cinco na escola 2 (duas noturnas e três diurnas). O jogo foi aplicado após terem sido ministradas as aulas sobre fórmulas estruturais planas e a nomenclatura dos alcanos e realizada uma avaliação (avaliação prévia). Antes de iniciar o jogo, os professores esclareceram aos alunos que não se tratava de uma disputa, com vencedores e perdedores, mas sim, uma situação de ensino e aprendizagem em que todos venceriam, pois ocorreria uma revisão do assunto sobre Química Orgânica de uma maneira alternativa, dinâmica, interativa e divertida.

Para a aplicação do jogo, a turma foi dividida em várias duplas. O professor montou as duplas com alunos que sentavam distantes uns dos outros na sala de aula, para que estes se socializassem melhor.Com esta estratégia, visou-se ampliar as interações entre os estudantes. Depois que os alunos se apropriaram das regras, o jogo foi iniciado.

A obtenção dos dados para analisar o jogo didático ocorreu através de levantamentos qualitativos e quantitativos. As observações comportamentais dos alunos durante o jogo foram registradas através de diário de campo e gravações de áudio. Suas 
interpretações receberam uma abordagem qualitativa segundo as recomendações de Bogdan e Biklen (2000). A importância destas observações comportamentais também é foram descritas por Mello (2011), reforçando a sua aplicação no momento do jogo:

[...] a pesquisa qualitativa é um tipo de pesquisa onde o pesquisador pode ser o interpretador de uma realidade, sendo capaz de descrever fenômenos e comportamentos além de fazer citações diretas de pessoas envolvidas na pesquisa e interagir com indivíduos, grupos e organizações. (MELLO, 2011, p. 76).

Para a análise quantitativa foi aplicado duas avaliações de dez questões cada, uma antes e outra após o uso do jogo didático. A primeira avaliação envolveu os conceitos de alcanos e para a segunda avaliação os conceitos foram alcanos, alcenos e alcinos. A pesquisa quantitativa seguiu as recomendações de Fonseca (2002), que estabelece:

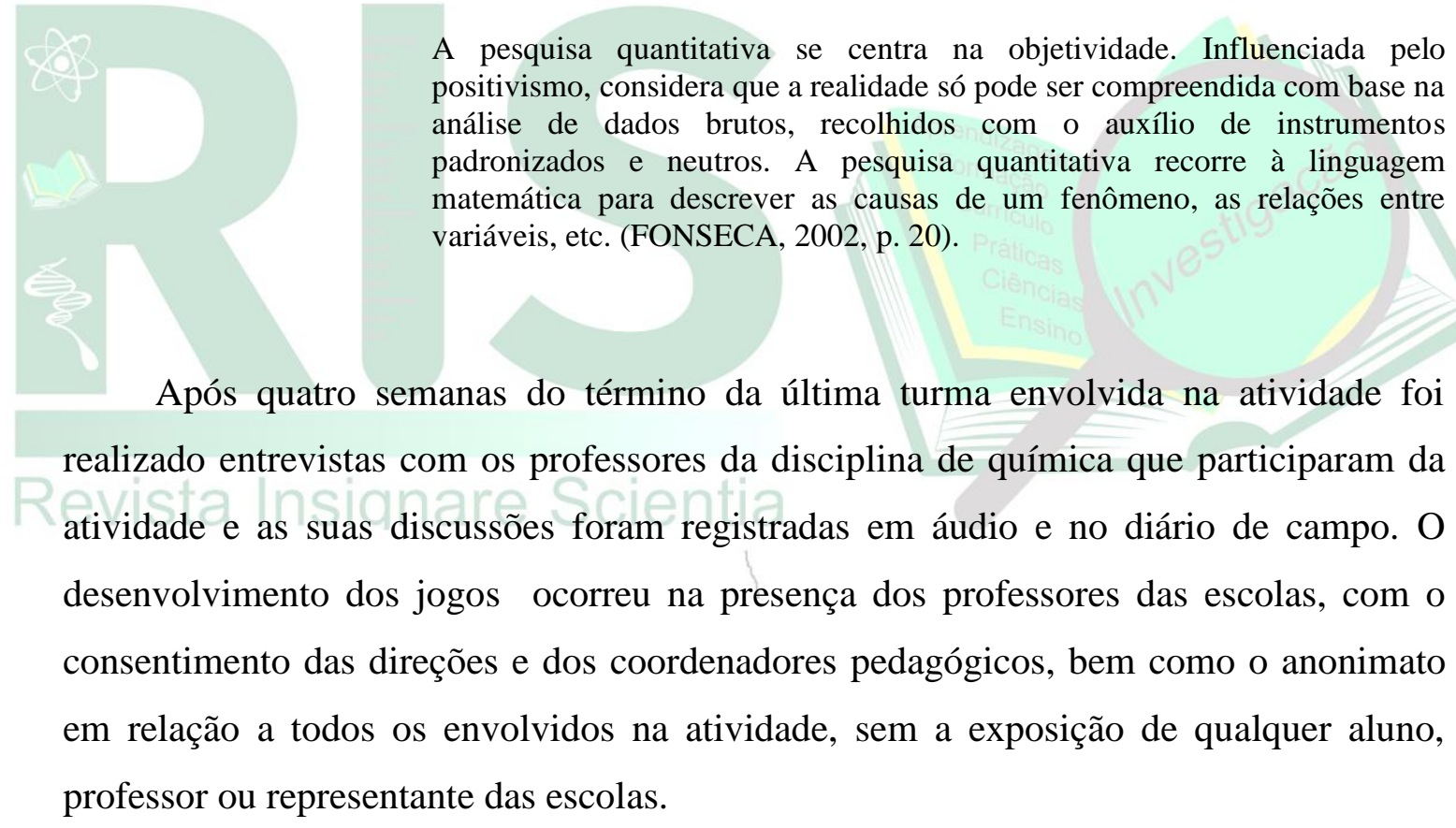

\section{RESULTADOS E DISCUSSÃO}

Através de uma avaliação prévia dos alunos, observamos uma dificuldade sobre o domínio significativo envolvendo os conceitos discutidos. A tabela 1 ilustra o número alto de erros apresentados nas avaliações.

Tabela 1 - Porcentagem das avaliações dos alunos por salas analisadas antes da aplicação do jogo didático. 


\begin{tabular}{|c|c|c|c|c|}
\hline Escola & Turma & $\%<4,0$ & $\%$ 4,0 a 7,0 & $\%>7,0$ \\
\hline \multirow{3}{*}{1} & $3^{\circ}$ A noturno & 26 & 53 & 21 \\
\hline & $3^{\circ} \mathrm{B}$ noturno & 30 & 52 & 18 \\
\hline & $3^{\circ}$ A diurno & 11 & 48 & 41 \\
\hline \multirow{5}{*}{2} & $3^{\circ}$ A noturno & 33 & 55 & 12 \\
\hline & $3^{\circ} \mathrm{B}$ noturno & 31 & 54 & 15 \\
\hline & $3^{\circ}$ A diurno & 15 & 63 & 22 \\
\hline & $3^{\circ} \mathrm{B}$ diurno & 11 & 60 & 29 \\
\hline & $3^{\circ} \mathrm{C}$ diurno & 12 & 58 & 30 \\
\hline
\end{tabular}

Fonte: Autoria própria.

A interpretação dos resultados destas avaliações nos indica que os maiores acertos ocorreram nas turmas com o período diurno, no qual a média de acertos está na faixa de 4,0 a 7,0 e com uma melhora na faixa maior que 7,0 em relação ao período noturno. Porém, o fator preocupante nesta análise é o número considerável de alunos que apresentaram resultados inferiores a 4,0, principalmente no período noturno, ilustrando que a aprendizagem para estes alunos não foi significativa. Esses resultados corroboram as observações já apresentadas por Matos et al. (2009), no qual descrevem que a simples memorização das denominações, das regras e das classificações são esquecidas pelos estudantes rapidamente.

$\mathrm{Na}$ aplicação do jogo didático, após as discussões do conteúdo pedagógico em aula anterior, constatou-se que a presente proposta pode representar uma alternativa para revisão de conceitos, que exijam memorização, tais como as funções orgânicas e de regras de nomenclatura. Através dos registros em diário de campo observou que os alunos foram receptivos a atividade. Conforme relato dos professores ocorreram mais questionamentos em relação ao conteúdo teórico do que apresentados em aulas anteriores pelos alunos, esta interação também ocorreu nas discussões entre os alunos para optar pela melhor resposta as questões levantadas pelas cartas. Como exemplo temos a transcrição de uma discussão apontada pelos alunos em relação ao posicionamento de um radical metil:

\section{“- Esta molécula tem um radical, só pode ser neste local.”- Aluno AHT}


“- Não. Pode ser em qualquer lugar pela molécula, pois não aparece o número de onde está. Pode ocupar todos estes lugares aqui." - Aluna AMV

“- Verdade, estou lembrando do que o professor falou na aula. Como será que eles montaram?" - Aluno AHT

“- Olha. Só pode ser aqui, pois neste espaço não caberia a molécula. Tem "água” aqui." - Aluna TOAA

“- Sim. Nossas chances melhoram se optarmos por este quadrado. Vamos ver pessoal?" - Aluna AMV

Conforme as observações dos relatos dos alunos, verificamos que ocorreram uma construção de argumentos em relação a teoria apresentada em aula anterior, as dúvidas estão sendo compartilhadas e as soluções apontadas pelos próprios alunos, gerando uma discussão dinâmica e saudável no aprimoramento das regras e das estruturas moleculares orgânicas. Estas discussões aconteceram durante toda a aplicação da atividade, consolidando como um jogo didático no sentido de reverem os conteúdos.

A construção das equipes entre os alunos que geralmente não fazem as tarefas juntos foi um ponto positivo na aplicação do jogo didático, pois a socialização é importante para a formação cidadã dos alunos. De acordo com Pinto (2014), é essencial que ocorra essa interação social entre todos os indivíduos da sala de aula.

A interação em qualquer ambiente nasce da aceitação do outro onde o respeito e o acolhimento facilita a convivência entre os seres humanos. $\mathrm{Na}$ escola, o ambiente das relações interpessoais, deve estar focalizando a constituição do eu, a compreensão do indivíduo com suas diferenças e qualidades, para ter condições de vida em grupo (PINTO, 2014, p. 27).

Durante as discussões com os professores envolvidos no projeto foi relatado que vários alunos nas aulas seguintes comentaram sobre o jogo, e que principalmente os ajudaram a uma melhor revisão sobre esses conceitos, e incentivaram nas memorizações das montagens de estruturas e nas regras de nomenclatura para as outras funções em química orgânica.

Por meio de transcrições das aulas nas quais as atividades foram aplicadas, é possível apontar algumas falas dos estudantes que corroboram o feedback dos docentes em relação a melhora na memorização.

"Sempre tive problemas em decorar, mas com este jogo ficou mais fácil" - Aluna

Recebido em: 13/07/2021

$\mathrm{BBC}$

Aceite em: 17/09/2021 
"Tudo que tenho que ficar gravando amanhã já esqueço, só guardo algo que preciso mesmo, pois tenho dificuldade em fazer isso" - Aluno AAGH

"Como adoro biologia fico sempre lendo o livro e acabo gravando sem mais dificuldades, o que não é o caso da química, mas assim, com este jogo é bem mais interessante e acabei memorizando mais rápido estas regras" - Aluna RRC

As análises do diário de campo, demonstraram também que, além de facilitar a memorização, o jogo didático estreitou a afetividade entre os alunos e os professores que, sem dúvida, é um aspecto tão importante quanto o pedagógico. Durantes as partidas os pesquisadores questionaram os estudantes sobre o hábito de direcionar as dúvidas aos professores, e muitos alunos afimaram que durante a aula não faziam isso, mas que com o ambiente descontraído proporcionado pelo jogo, isso se tornou mais fácil e até já tinham perguntado diversas vezes aos professores algumas dúvidas sobre os conceitos e suas interpretações sobre as questões das cartas.

"Acho que perdi o medo de perguntar ao professor, ele é até muito atencioso" -

\section{Aluno AMGH}

“Durante o jogo a gente fica mais à vontade para falar, se errar ninguém fica

repreendendo. Gosto mais desta forma, pois pude perguntar coisas que geralmente não pergunto ao professor" - Aluno NOOR

“Como aqui no jogo não ficam te olhando e aquele silêncio todo, a gente, sabe né, pode perguntar besteiras da matéria (risos)" - Aluno SST

Em relação ao conteúdo didático, alguns alunos tiveram durante a aplicação do jogo, uma melhora significativa na montagem das moléculas orgânicas, prestaram atenção em como a valência (número de ligações entre os átomos), é utilizada nas estruturas. Temas estes, sempre descritos pelos professores, como sendo obstáculos para um entendimento nos estudos envolvendo a química orgânica, conforme as observações dos resultados obtidos na avaliação prévia e sobre a evolução na segunda avaliação. A tabela 2 ilustra as porcentagns dos alunos em relação ao acerto sobre a segunda avaliação, que neste caso, continha conteúdos de alcanos, alcenos e alcinos.

Tabela 2 - Porcentagem das avaliações dos alunos por salas analisadas depois da aplicação do jogo didático.

\begin{tabular}{lllll}
\hline Escola & Turma & $\%<4,0$ & $\%$ 4,0 a 7,0 & $\%>7,0$
\end{tabular}

Recebido em: 13/07/2021

Aceite em: 17/09/2021 


\begin{tabular}{lllll}
\hline & $3^{\circ}$ A noturno & 08 & 60 & 32 \\
$\mathbf{1}$ & $3^{\circ}$ B noturno & 12 & 62 & 26 \\
& $3^{\circ}$ A diurno & 04 & 44 & 52 \\
\hline & $3^{\circ}$ A noturno & 11 & 65 & 24 \\
& $3^{\circ}$ B noturno & 10 & 61 & 29 \\
& $3^{\circ}$ A diurno & 05 & 54 & 41 \\
& $3^{\circ}$ B diurno & 04 & 51 & 45 \\
& $3^{\circ}$ C diurno & 04 & 48 & 48 \\
\hline
\end{tabular}

Fonte: Autoria própria.

Vale destacar os aspectos cognitivos que foram trabalhados no jogo e que subsidiam a aprendizagem de conceitos abstratos e de maior complexidade, o que possibilitou aos estudantes aprofundar relações entre os conceitos explorados na atividade lúdica de maneira criativa, conforme as constatações nas análises da pesquisa qualitativa, as anotadas em diário de campo.

As análises do diário de campo durante as partidas, ilustrou que muitos alunos apresentaram dificuldades em relacionar algumas propriedades dos alcanos com o seu cotidiano, por exemplo a carta de número 29 apresentava a pergunta: "Qual o estado físico em que comercialmente o GLP (Gás liquefeito de petróleo) é armazenado?” A maioria dos alunos ao lerem esta carta, responderam gasoso, e não líquido, como é usualmente vendido no comércio. Alguns alunos optaram pela terceira alternativa, estado sólido, indicando que não houve uma observação na relação entre as alternativas e o seu cotidiano, como o fato do botijão de gás em sua residência, ao chacoalhar é evidente que nota-se um líquido armazenado. Simplesmente como o estado do GLP é gasoso em temperatura ambiente, e é o gás liberado no fogão, a maioria dos alunos optaram erroneamente nesta questão. Os alunos ao questionarem a alternativa correta durante o momento de discussão, evidenciam a importância das relações teóricas e cotidianas para uma melhor aprendizagem, corroborando ao trabalho de Silva; Cordeiro e Kill (2015).

"Nossa, nunca pensei nisso, que lá dentro tá líquido. Quer dizer que se balançar notamos o líquido de butano e de propano? Fala sério (risos)" - Aluno BDF 
"Poxa, devo prestar mais atenção no que ocorre a minha volta. Tem muita ciência em casa e nunca percebia, principalmente com a química" - Aluna AMC

Outro exemplo sobre a atividade e sua importância para a revisão de conceitos foram as discussões que ocorreram referente a carta de número 17, que tem a seguinte pergunta: "Por que os alcanos são solúveis em etanol?" A resposta correta, solventes fracamente polarizado, não foi interpretada pelos alunos. Todas as respostas apresentadas pelos jogadores foram em relação ao solvente apolar, devido os alcanos serem apolares. Apesar de nenhum grupo indicar o solvente polar, como a água, mesmo assim demonstra que houve uma convicção errônea sobre a força da polaridade do etanol. Nas discussões com os alunos observou-se que quando os professores discutiram este conceito em sala de aula, não ocorreu uma efetiva aprendizagem.

A atividade proposta auxiliou na verificação dos possíveis problemas de aprendizagem dos alunos, possibilitando que os professores adotem metodologias diferenciadas para recuperar a aprendizagem desse objeto do conhecimento e também que modifiquem suas condutas para as discussões futuras.. A transcrição de um dos docentes sobre o assunto reforça a importância destas avaliações coletivas e descontraídas em sala de aula, e assim o docente pode verificar melhor quais as dificuldades de aprendizagem dos alunos perante cada conteúdo.

"O jogo foi muito importante para verificar se os alunos compreenderam as questões que estávamos discutindo em sala de aula. Em uma prova convencional que aplico, com alternativas, realmente não consigo verificar se os alunos apreenderam. Vi com esta atividade que a avaliação foi muito mais importante para mim do que para os alunos, pois me norteou o que farei no futuro, modificando minha postura como professor. Me ajudou a repensar em como trabalhar em sala de aula e a analisar melhor as falhas dos alunos" - Professora SHAB

Uma descrição importante relatada nas entrevistas aos professores foram suas observações em podere verificar quais os maiores problemas de aprendizagem dos alunos, conhecer melhor as suas dificuldades e indicar uma sinalização de como podem ser resolvidas nas aulas posteriores. A aplicação do jogo didático com estes professores contribuiu para incentivá-los a novas formas de discutir e aplicar conceitos em sala de aula e as suas possibilidades pedagógicas. Conforme relatado em diário de campo. 
"Nas aulas, geralmente pergunto se tem alguma dúvida, mas quase sempre nenhum aluno diz nada. Só posso ver sua evolução nos momentos de avaliação, e as provas não dá para discutir conceitos com os alunos, é certo ou errado. Com esta atividade pude perceber melhor como eles pensam e quais as suas dificuldades na aprendizagem. Um jogo torna o ambiente muito relaxado e os alunos se expressão mais verdadeiro, sabe né, na aula eles falam tudo certinho para não chamar atenção, no jogo eles falam sem medo e dizem realmente como pensam e neste ponto é importante para verificar realmente como eles estão interagindo com o conteúdo" - Professora

\section{MOS}

Outros pontos foram alcançados com a aplicação do jogo didático, como por exemplo, a socialização de grupos heterogêneos e que não tinham o hábito de fazerem tarefas juntos. Os alunos ainda informaram que foi muito significativo esta oportunidade para conhecerem melhor os colegas de sala e principalmente em poder respeitar as opiniões dos demais, a discutir com argumentos, pois o jogo, o assim necessitava para que as equipem pudessem vencer. Um relato de um aluno chamou a atenção conforme o registro em diário de campo sobre estas considerações.

"Em todos esses anos que estive na escola sempre achei a aluna FTRI como chata, sempre respondia tudo aos professores, parece que queria se aparecer. Depois deste jogo e das conversas percebi que ela é muito legal, sabe esperar sua fala. Passamos a fazer amizade agora, inclusive até fui na sua casa. Por isso quero agradecer a esse pessoal que fizeram isso aqui na sala, puderam nos fazer uma amizade" - Aluna VSSAF

Os relatos observados reforçam a importância do emprego de diferentes metodologias no processo de ensino e aprendizagem aos alunos. Estas observações alinham-se as ideias de Cunha (2012), na qual propõem que os jogos didáticos possibilitam aos estudantes modos diferenciados para aprimorar conceitos mais abstratos ou decorativos, formação cidadã e social, e aos professores uma melhor compreensão da aprendizagem dos alunos e suas deficiências.

\section{CONCLUSÃO}


O jogo didático "Batalha Química" foi uma proposta alternativa, lúdica e interessante para alunos do ensino médio na revisão de fórmulas estruturais, nomenclatura e propriedade dos alcanos, permitindo-os rever conceitos iniciais de hidrocarbonetos, em Química Orgânica, de maneira mais dinâmica, atrativa e contextualizada.

A interação social entre os alunos, as discussões argumentativas entre os indivíduos dos grupos, as escolhas de suas respostas são fatores positivos para um ambiente escolar mais descontraído e dinâmico. A possibilidade de o próprio professor elaborar as questões que acham mais pertinentes ao conteúdo, por si só, garante que a atividade seja nivelada de acordo com os conhecimentos prévios dos alunos. $\mathrm{O}$ ensino de Química Orgânica em nível médio é um desafio para os professores, pois o volume de assuntos é bastante amplo. A aplicação de uma atividade lúdica, por docentes que não conheciam esta ferramenta, como mecanismo para rever conceitos pedagógicos através de uma maneira mais descontraída, promotora de diálogos e no aumento do interesse pelos alunos, fez com que estes profissionais pudessem observar a importância que o uso de outras propostas metodológicas pode contribuir para a formação do aluno.

\section{REFERÊNCIAS}

AMADO, J. Universo dos Brinquedos Populares. Quarteto: Coimbra, 2007.

AMARAL, A. M.; MENDES, A. N. F.; PORTO, P. S. S. Jogo roletrando como metodologia alternativa no ensino de química. Experiências em Ensino de Ciências, v. 13, n.1, p. 225-240, 2018.

ANTUNES, M.; PACHECO, M. A. R.; GIOVANELA, M. Design and implementation of an educational game for teaching chemistry in higher education. Journal of Chemical Education, v. 89, n. 4, p. 517-521, 2012.

BENEDETTI FILHO, E.; BENEDETTI, L. P. S. Emprego de atividades lúdicas no ensino de química. Sorocaba: Editora Cidade, 2015.

BENEDETTI FILHO, E.; BENEDETTI, L. P. S.; FIORUCCI, A. R.; MOTA, J. S.; PINHO, E. C. Proposta de uma sequência didática focada na leitura de textos e no jogo de sete erros químicos para o ensino de nível representacional de química orgânica.

Experiências em Ensino de Ciências, v. 12, n. 6, p. 261-278, 2017.

Recebido em: 13/07/2021

Aceite em: 17/09/2021 
BENEDETTI-FILHO, E.; CAVAGIS, A. D. M.; SANTOS, K. O.; BENEDETTI, L. P. $\mathrm{S}$. Um jogo de tabuleiro envolvendo conceitos de mineralogia no ensino de química. Química Nova na Escola, v. 43, n. 2, p. 167-175, 2021.

BOGDAN, R.; BIKLEN, S. Investigação qualitativa em educação. Porto: Porto Editora, 2000.

BÜDY, B. Fatty acid-containing lipid puzzle: a teaching tool for biochemistry. Journal of Chemical Education, v. 89, n. 3, p. 373-375, 2012.

COLOMBO, D. A. Jogos didáticos como instrumentos de ensino. Revista Insignare Scientia, v. 2, n. 3, p. 78-83, 2019.

CUNHA, M. B. Jogos no ensino de química: considerações teóricas para sua utilização em sala de aula. Química Nova na Escola, v. 34, n. 2, p. 92-98, 2012.

EASTWOOD, M. L. Fastest fingers: a molecule-building game for teaching organic chemistry. Journal of Chemical Education, v. 90, n. 8, p. 1038-1041, 2013.

FELÍCIO, C. M.; SOARES, M. H. F. B. Da intencionalidade à responsabilidade lúdica: novos termos para uma reflexão sobre o uso de jogos no ensino de química. Química Nova na Escola, v. 40, n. 3, p. 160-168, 2018.

FONSECA, J. J. S. Metodologia da pesquisa científica. Fortaleza: UEC, 2002.

KAVAK, N. ChemOkey: a game to reinforce nomenclature. Journal of Chemical Education, v. 89, n. 8, p. 1047-1049, 2012.

KAVAK, N. ChemPoker. Journal of Chemical Education, v. 89, n. 4, p. 522-523, 2012.

KISHIMOTO, T. M. O brinquedo na educação: considerações históricas. Série Ideias, nº 7, São Paulo: FDE, 1995.

LARSON, K. G.; LONG, G. R.; BRIGGS, M. W. Periodic properties and inquiry: student mental models observed during a periodic table puzzle activity. Journal of Chemical Education, v. 89, n. 12, p. 1491-1498, 2012.

MACHADO, M. M.; BUZANELLO, C. A. F.; HAMMERL, P. C. Jogo de cartas como metodologia de ensino de astronomia para a educação básica. Revista Insignare Scientia, v. 3, n. 2, p. 539-550, 2020.

MARISCAL, A. J. F.; MARTÍNEZ, J. M. O.; MÁRQUEZ, S. B. An educational card game for learning families of chemical elements. Journal of Chemical Education, $v$. 89, n. 8, p. 1044-1046, 2012.

MATOS, A. C. S.; TEIXEIRA, D. D.; SANTANA, I. P.; SANTIAGO, M. A.; PENHA, A. F.; MOREIRA, B. C. T.; CARVALHO, M. F. A. Nomenclatura de compostos orgânicos no ensino médio: influência das modificações na legislação a partir de 1970

Recebido em: 13/07/2021

Aceite em: 17/09/2021 
sobre a apresentação no livro didático e as concepções de cidadãos. Química Nova na Escola, v. 31, n. 1, p. 40-45, 2009.

MELLO, A. C. K. A. de. O grupo focal como fonte de coleta de dados em pesquisas qualitativas. In: VII ENCONTRO DO GRUPO DE PESQUISA "EDUCAÇÃO, ARTE E INCLUSÃO”, 2011. Anais..., 2011.

MOREIRA, R. F. A game for the early and rapid assimilation of organic nomenclature. Journal of Chemical Education, v. 90, n. 8, p. 1035-1037, 2013.

NALLIN, C. G. F. Memorial de formação: o papel dos jogos e brincadeiras na educação infantil. Campinas-SP, 2005.

OLIVEIRA, J. S.; SOARES, M. H. F. B.; VAZ, W. F. Banco químico: um jogo de tabuleiro, cartas, dados, compras e vendas para o ensino do conceito de soluções. Química Nova na Escola, v. 37, n. 4, p. 285-293, 2015.

OLIVEIRA, S. G.; CALEJON, L. M. C. O jogo torre de Hanói para o ensino de conceitos matemáticos, REnCiMa, v. 7, n. 4, p. 149-158, 2016.

PARLETT, D. History of board games. Echo Point Books \& Media: Oxford, 2018.

PINTO, M. F. R. As relações interpessoais e a aprendizagem. Monografia (Curso de Especialização Fundamentos da Educação) - Universidade Estadual da Paraíba. Itaporanga. 2014.

SILVA, B; CORDEIRO, M. R.; KIILL, K. B. Jogo didático investigativo: uma ferramenta para o ensino de química inorgânica, Química Nova na Escola, v. 37, n. 1, p. 27-34, 2015. 